\title{
Alessandra Flores D’Arcais, Il «Voyage en Icarie» di Etienne Cabet
}

\section{Rita Severi}

\section{Q OpenEdition}

1 Journals

\section{Edizione digitale}

URL: https://journals.openedition.org/studifrancesi/40873

DOI: 10.4000/studifrancesi.40873

ISSN: 2421-5856

\section{Editore}

Rosenberg \& Sellier

\section{Edizione cartacea}

Data di pubblicazione: 1 juillet 2004

Paginazione: 206

ISSN: 0039-2944

\section{Notizia bibliografica digitale}

Rita Severi, «Alessandra Flores D'Arcais, I/ «Voyage en Icarie» di Etienne Cabet», Studi Francesi [Online], 142 (XLVIII | I) | 2004, online dal 30 novembre 2015, consultato il 09 septembre 2021. URL: http:// journals.openedition.org/studifrancesi/40873; DOI: https://doi.org/10.4000/studifrancesi.40873

Questo documento è stato generato automaticamente il 9 septembre 2021.

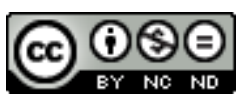

Studi Francesi è distribuita con Licenza Creative Commons Attribuzione - Non commerciale - Non opere derivate 4.0 Internazionale. 


\title{
Alessandra Flores D'Arcais, Il «Voyage en Icarie» di Etienne Cabet
}

\author{
Rita Severi
}

\section{NOTIZIA}

ALESSANDRA FLORES D’ARCAIS, Il «Voyage en Icarie» di Etienne Cabet, Padova, Cleup, 2002, pp.

304.

1 Alla stupenda mostra intitolata «Utopia. The Search for the Ideal Society in the Western World», che si è svolta alla New York Public Library dal 14 ottobre 2000 al 27 gennaio 2001, era esposta una litografia a penna di Albert d'Arnould, La Foire aux idées, apparsa sul numero 37 del Journal pour rire nell'ottobre del 1848, che illustrava la grande euforia dopo i moti rivoluzionari. Su di un palcoscenico da fiera, uno dopo l'altro, compaiono, come tanti imbonitori, i grandi riformatori dell'epoca. In primo piano, a sinistra, su di un estemporaneo palcoscenico, si nota Etienne Cabet (1788-1856), che indicando una carta geografica, descrive e loda la sua immaginaria Icaria, della quale, secondo il malizioso illustratore, è capitale Charenton, luogo allora noto per essere la sede del più grande manicomio di tutta la Francia. Era possibile anche vedere e toccare con mano altro materiale «icariano»: per esempio, il manoscritto, conservato presso la BNF, che riproduce il disegno a colori della bandiera, molto simile a quella odierna della pace che svetta ancora da tante finestre italiane, eccetto che la scritta in mezzo era «FRATERNITE'». Ancora più interessante è il disegno della comunità di Nauvoo, Illinois (conservato presso la NYPL) luogo scelto dopo il fallimento dell'insediamento nel Texas. Il denso volume della Flores D’Arcais utilizza molto materiale, sia edito (non proprio aggiornato), sia inedito (tra il quale era opportuno operare una scelta oculata), ma, o perché gravato da troppa erudizione, o perché l'analisi si sposta su troppi livelli (sociale, linguistico, comparativo), alla fine non rende giustizia all'avventura di Cabet, né fa chiarezza sul Voyage en Icarie (1840) e sul vasto repertorio della letteratura utopistica. In Icaria tutto viene pubblicizzato, ogni evento è registrato dal dipartimento di statistica, eppure nell'analisi del Voyage l'A. sembra del tutto refrattaria ad elaborare 
ed estrapolare da un contesto così adatto una retorica del linguaggio pubblicitario ante litteram. L'analisi linguistica inoltre è ben lontana dall'essere rigorosa. Basti aggiungere che la parola francese «communisme» «nel senso moderno del termine» (p.37), il cui uso corrente viene fatto risalire dall'A. al 1840 (ma nessun dizionario etimologico viene citato) doveva situarsi per Cabet, e per gli utopisti come lui, in un periodo rivoluzionario molto antecedente. Un'indagine più approfondita forse condurrebbe verso la rivoluzione inglese del 1640 e alle utopie dei levellers i quali, come risulta dagli studi di Christopher Hill, già utilizzavano il discorso del comunismo. Infine, tra le tante congetture che l'A. propone per spiegare il topos del viaggiatore inglese perché non includere anche la possibile derivazione da un altro viaggio utopico, per es., A Description of the Famous Kingdom of Macaria (1641) di Samuel Hartlib e Gabriel Plattes? Dopotutto, Cabet meditò a lungo al British Museum e qualcosa deve aver pur assimilato. Dispiace infine che in un libro così fitto di citazioni manchi un indice dei nomi. 